\title{
Exploring Policy Options for a New Rural America: Conference Synthesis
}

\author{
S. R. Johnson \\ Iowa State University, Ames, Iowa
}

\section{INTRODUCTION}

This Conference has more then lived up to its billing, exploring policy options for a new rural America but in addition identifying the basis for a new framework for rural policy. Evidence that a new policy framework is needed is abundant (Stauber). In one way or another, rural areas of North America and of most of the developed world have for at least the past century experienced secular decline compared to urban areas. This has occurred during a period of high government transfers or subsidies, both direct and from policy interventions that have distorted the functioning of markets. It is clear that the systemic discrepancy between rural and urban populations/areas is a public policy priority. It is just as clear that there has not been a consensus on how to address these development and economic issues. Much funding and technical assistance has been allocated with little apparent impact on the condition of rural areas and rural people.

Four pillars of an emerging new rural policy framework have surfaced during the Conference. They are found in the first paper by Stauber and in one way or another, although not always in the same terms, reinforced and elaborated in the subsequent papers and discussions. These pillars are place competitiveness, differentiation and place policy, local expression and differentiation and strategic behavior. In this synthesis, we develop these concepts drawing from the Conference papers and the related discussion. As will be apparent, the emerging framework suggest policy approaches far different than those we might identify as the current de facto rural policy for North America. The framework will also reveal why most past attempts at devising an effective rural policy have failed.

The synthesis is organized to develop the ideas forming the foundations for the four pillars. In the related sections, we will first draw on the papers to develop and elaborate the associated ideas. Then in a final section, we set forth the integrated policy framework that is implied by the interesting and provocative themes from the Conference papers and discussion. The implication of this policy framework is for a major change at all government levels in way we address rural issues - federal, state and local. The strategic behavior and game theoretic based approach to rural policy helps make clear the differences in the policy roles and tactics at higher and more local levels of government. As well it helps to understand the interrelationships among rural places - which given the new policy framework grow and prosper because they are not like one another.

\section{PLACE COMPETITIVENESS}

In retrospect it is rather surprising that place or territory as termed the European participants in the Conference, has emerged so slowly as rural policy concept. A first possible explanation is the strongly held individualistic value structure present in many of the developed nations and in particular, in the United States (US). This Jeffersonian tradition is reflected in many of the policies that have been directed to and/or have impacted the rural areas. Quality public education that is accessible to all, infrastructure equalization between rural and urban areas (electricity, roads, water, and currently digital communication - per the Conference paper by Malecki, etc.) are all elements of a policy designed to increase access to and support for a system in which individuals can achieve their full potential. These policies as manifested in the land grant system have been argued to have especially benefited agriculture and those who have succeeded at agriculture in rural areas (D. Gale Johnson, Huffman and Evenson).

These Jeffersonian policies have tended to make places more similar in terms of individual opportunity. That is, they minimize the importance of place and or are designed to make all places equally competitive. As well they are really not rural policy but a national policy which has resulted in disproportionately public investment in places that are sparsely populated leading to special market failures. It is easy to fall into the trap of believing that this national policy which may be differently administered in rural areas is in fact a rural policy. Instead, it reflects a national priority on a common social backbone for all places.

A second possible explanation that is developed in the papers by Stabber and Steifelmeyer Martin is the apparent preoccupation with industry policy for agriculture and manufacturing - the two major contributors to the economic base for rural communities, as a rural development policy (Johnson and Martin). These policies often invented in times of crisis are difficult to change due to the strong political rent seeking interest groups that form to assure they are maintained. A good example is the 1930s-based policy for agriculture in the US. Close to $\$ 70$ billion in direct federal subsidies was transferred to US agriculture during FY99-FY2001 (Johnson, 2001). It is well known that these transfers go mainly to the farmers who have higher incomes than average rural and urban residents, and that they are largely capitalized into the price of land nearly 50 percent of which is owned by non-farmers. Yet the policies and the political will to maintain them has persisted. The state and local role in industry policy 
for agriculture, except for agribusiness (see manufacturing below) has been minor.

For manufacturing, the federal subsidies have implemented more on the taxation and trade sides, and state and local communities have played a greater role in policy. Investment tax credits and trade protection are examples of federal instruments. Relocation bribes and tax municipal bonding authorities are good examples of these policies at state or local levels. Again these policies persist in the face of strong evidence that they do not support development and growth in the targeted geographical areas. It is the rent seeking interest groups and their interaction in the political arena that sustain these policies.

In summary, individualistic and industry policies have been the major tools advocated for improving the lot of rural areas. Both are in fact not rural policy since they are not directed to geographic areas. The individualistic policies have the effect of reducing the importance of place or making all places equally competitive. The industry policies have a coincidental connection with place. In fact, the evidence is that industry policies limit the opportunities for economic growth and development of rural areas. Per the paper by Steifelmeyer and Martin, these policies in the US have slowed the development of a consumer driven "product" agriculture compared to "commodity" agriculture that is more in the interest of the present agribusiness industry structure, limiting the products that reflect special attributes of places.

Place competitiveness relates to the attributes of communities or areas that make them attractive to households that are sources of human and social capital and early in the product cycle firms. Distance or space is as well a critical element of place policy. It is clearly a differentiating factor that distinguishes between communities. The new economic geography has recognized the concept of space in explaining the location of people and economic activity (Krugman and Kilkenny). But there are other factors that distinguish places form one another and that effect their competitiveness. Markets do not exist for many of these attributes, suggesting an important role for public action. These attributes are important however, if they are attractive inducements to choice of place location. The implication is that if rural areas are not places where people who can choose where they live want to live, sustained development is not likely.

Place competitiveness and policy require instruments and institutions that are different than those in the current de facto rural policy tool kit. This idea also helps to understand that many of the existing policies designed to support rural development must be changed. They are at odds with the concept of place competitiveness. Taking agriculture as an example, attention should be given to the rent seeking interest groups that hold the industry policies in place and direct subsidies in ways counter to development strategies that have place as a central concept. Residents of rural communities should ask hard questions about commodity check off and other programs that reinforce the power of the rent seeking special interest groups. For manufacturing, similar types of questions should be asked by rural residents but about relocation bribes and other concessions designed to attract manufacturers that have products well along in the product cycle.

Place policy is by nature designed to build on the uniqueness of communities or locations. Again the rationale for public action is that the attributes that are special to place often do not lend themselves to efficient market allocation. This means that place policy must be much more location specific than simply developing rural versus urban areas and/or populations. Place policy is by nature designed to build on the uniqueness of communities or location Again the rationale for public action is that the attributes that are special to place often do not lend themselves to efficient market allocation. This means that place policy must be much more location specific than simply developing rural versus urban areas and/or populations. Place policy is not inconsistent with the individualistic policy that has been a part of the rural development strategy in the US. Many of the infrastructure and related interventions generate attributes of locations that are desirable to firms and households. For example in the modern economy, places with out broad band internet connection are not likely to attract households that include educated and entrepreneurial members. Thus it is a uniqueness that is beyond some acceptable level of base public and private services that defines a competitive rural community or place. This uniqueness can be see as the analog of product differentiation in markets for goods and services. Just as differentiated products command a higher price, communities that are differentiated have higher value and other things equal, sell better to prospective firms and households.

\section{DIFFERENTIATION AND PLACE POLICY}

How are places different? There are of course many answers. The fact that there are many answers is good news for the new rural development policy. It means that there are many potential opportunities for organizing a community or location to differentiate it from others in ways that are appealing to a segment of the households and firms that are in the market to choose their locations. But we can give the concept a little more structure than is implied by these general ideas.

One way to begin to develop the idea of differentiation is to consider the attributes of places that are not under the control of the communities or regions as distinguished from those that are under their control. Even this simple classification has complications however. Distance between communities or regions is not a controllable attribute, but has become less important due to transport, infrastructure and other investments and technologies. In fact, the settlement patterns of the 
rural America were in many ways determined by distance. That is, distance was perhaps the primary attribute for differentiating communities and regions. One might argue that rural communities have not recognized that differentiation and not distance was the reason for their existence in the first place, and that they will have to differentiate themselves in other ways than distance if they are to survive and prosper.

Attributes that are often identified as not controllable by the leaders of the communities or region are largely physical. Mountains, oceans, rivers, interstate highways, ethnic origin of populations, railroads and climate are examples of attributes that are at least not controllable in the short run. Communities also have cultures that are unique and not easily changed. Attributes that can be changed are the likely targets for rural development policy. Examples of these include the leadership cadre and its capacities, the condition of the landscape, the capacities to capitalize on the natural and other endowments, and special new facilities and initiatives such as recreation centers, parks, community-wide special activities - settlers days or whatever.

At a more subtle level, communities or regions can address their competitiveness with policies that counter market failures that may be region or community specific. In a way, these initiatives are like industry policy, but localized. From this similarity, there is much to learn in terms of what will and will not work. Among these are the "growing the new economy and reinvigorating the traditional economy" initiatives discussed in the papers for the Conference. These include: manufacturing clusters that take advantage of agglomeration and other economies and networks that virtually achieve the same kinds of economies or administrative efficiencies (Rosenfeld), venture capital funds for new start ups and expansions of existing firms that are perhaps structured to support a diversified small business portfolio (Markley), new technologies introduced as utilities (Malecki), support systems and incubators for new firms and programs to develop the capacities of new entrepreneurs (Dabson), and supply networks for agricultural producers and processors that produce differentiated products (Steifelmeyer and Martin). It is difficult to add to these papers other than to offer the differentiation of communities or regions-places, as a unifying framework and place based market failures as a motivation for local interventions of these and other types.

The papers from our European colleagues offer another aspect to the idea of place. These initiatives can be seen in the context of differentiating the lifestyles of the communities. Rather than focusing on the development of the economy of an area through adding firms and increasing their chances of success, the approach is to market the differentiated lifestyle and culture. This is often combined with the return of the large scale landscape to dimensions that are consistent with the cultural attributes that are being emphasized and marked as the value added to life as a result of living in or touring and vacationing in the region or territory (Fabriziao). The governance structures that can facilitate the realization of these potentials are institutions about which we in North America have much to learn. Could the massive subsidies that now flow to agriculture in the name of rural development be used to establish regions or places as kinds of living parks?

Finally governance structures themselves are sources of differentiation. They as well must be competitive as a source of place differentiation. There has been much resistance to changing the governance structures that are in place in the rural areas. The concepts of place and differentiation offer new rationales for making changes in these structures. First, as identified in the papers from our European colleagues, the governance structures may require change to permit the capitalization on community attributes that are a source of differentiation and potential growth. Second, efficiency of governance is in itself a positive attribute of places. In many North American change of governance structure is seen as a sign of further decline. With the place based rural development policy it can be a sign of positive change.

\section{LOCAL EXPRESSION}

How do we identify the package of differentiating factors that add value to the region or community or its products? Here the idea that emerges particularly form the papers about the European experience is interestingly analogous to the way we now think of genes and the expression of traits in the plant and animal sciences. The communities have a history and culture that may not be fully expressed. This history and culture as well effects what the community or region can be or how it can change. The idea here is path dependence, where we are and will be is a function of where we have been. The lesson in all of this is that much of what a community can and will be is with the wisdom and culture of the local people and reflective of what has occurred in the past.

In the case of regions or territories for example, development policies must find ways of identifying the attributes of the communities that are different and then build on them. Much of this wisdom and the cultural uniqueness of places is resident in the local people - a part of the social capital of the community if we stretch the ideas in the material on this subject that is discussed by Stauber. This capital has to be identified and built on and then "invested" in ways that add to attributes of the community that are valued by the people, firms, governmental, and non governmental organizations who are existing or potential residents.

It is this source of the things that are really different about communities or regions that turns our modern approaches to rural development policy upside down. If we follow this line of reasoning the successful development policies or strategies will be quite community specific. Instead of trying to make 
rural communities have attributes like their urban counterparts, the idea is to build on what is unique and is a source of value to the residents of the communities. This approach argues for policy strategies that are supported by types of block grants to the communities rather than even state wide or national approaches. Here we are not referring the individualistic or national policies but to place policies.

It also argues for very different state policies, not the kind that have emerged where the subsidies are competitively awarded according to some image of what ought to be as viewed from the top down. The scope for federal and state activity is more related to the level playing field and individualistic policy approaches. A message from this Conference is that it is not these policy areas in which we find the real juice for the new rural economy. Instead, it is in the factors that make the rural places different. And that there is a major role for public action in this arena due to the market failures that exist for many of these attributes that are the potential for the future growth and identity of rural places.

Policy implications are for initiatives to address the failures in the markets for attributes, and for participatory exercises to identify and enhance the attributes of places that differentiate them form other places. In the former case, different governance and property rights structures may need to evolve. The place and differentiation pillars may make these kinds of changes easier to achieve. In the latter, technical assistance supplied by NGOs or by governmental groups like the Extension system of the land grants may be the catalysts for change. In all cases the potential for change and for confidence of the populations resident in the rural places will depend on the credibility and capacity to articulate the new foundations for rural development policy.

\section{STRATEGIC BEHAVIOR}

The ideas of place, differentiation and local expression all lend themselves to thinking about rural development in a more formalized strategic framework. The rural development policy process that will emerge from the implementation of the strategic approach will be yeasty and very different among regions or communities. The yeastiness will come form the active participation that will be required to assure that the attributes of the community that reside with the residents are expressed and used as key elements in the strategy. It will also come in the strategic behavior of the community leaders. Value created by the community through whatever mechanism is not independent from the initiatives of the competitive places whether neighbors or not. This is because the differentiation is in part defined in terms of the attributes and implicitly the development strategies of the competing places.

Strategic behavior and the formalization in the theory of games also offer an approach for studying alliances or cooperative actions among places.
Clearly, places however defined have possibilities for gain by cooperating or collaborating with other places. Often these opportunities are not exploited because the leaders do not understand how the structure the related negotiations. Mechanisms for collaboration and their negotiation are as well a part of the approach based on gaming principles. The fact that places may in fact be defined in terms of layers which intersect makes the understanding of the game structure and the implications of different mechanisms for cooperation within this context all the more important to the success of place based rural development strategies.

Fortunately there is a developing method for structuring decision problems of the type we have formulated with the ideas of place, differentiation and local expression. Modern game theory includes methods for dealing in such non-cooperative settings. As well the games can include multi stage and dynamic decision contexts. The value of these structures for formalizing the decision process and players strategies is not so much in the capacity to solve large numerical problems as in a way to think about the rural development problem that is at hand (see the paper by Barca for a good example). Most of the useful results form this decision approach come form stylised problem solutions that define effective ways to develop strategy and to design mechanisms for decisions that yield sustainable solutions. These formulations also guide the collection of data and empirical work that can aid in the decision making process.

A final aspect of the strategic behavior or game framework is the understanding that it imparts about contracting mechanisms. Within and among the communities or places there will have to be some kind of social contract if the development approach is to succeed. How do we structure these contracts recognizing that in a development strategy there is much uncertainty about the outcome? This means that the social and even the contracts between individuals are incomplete. This aspect of the contracts leads to various kinds of joint ownership in the outcomes or results (play offs) as mechanisms or building blocks for successful strategies. In common parlance this could imply types of innovative regional or place based governance structures.

The object here is not to digress into a discussion of strategic behavior and mechanism design but to identify the framework as one of use for addressing rural development as conceptualised by the speakers of the Conference and the license that has been taken with their ideas in this synthesis. In many ways the seeds of the strategic behavior approach are in all of the papers. Stauber has the "new strategic basis for rural development", Dabson has the idea of "entrepreneurial infrastructure" - helping the aspiring entrepreneurs to be good strategists and risk managers, Markley has the concept of community specific strategic development of venture capital, Rosenfeld includes the idea of networks and the mechanisms and strategies that are required to make them work, and Pezzini and Wojan focus on 
multifunctionality and negotiating strategies. There are other examples in the Conference papers and from the discussion. It is sufficient to note that strategy and mechanisms for negotiation and contracting are likely to be a big part of the new rural development policy framework.

\section{THE NEW FRAMEWORK}

The new rural development framework has at the center the concept of place. This distinguishes it from past approaches to rural development policy. These past approaches have been argues as having at their heart industry and individualistic policy. The former has only coincidental relationships to place. The latter is more a national that a rural place policy. We have come to think of it as a rural policy because its implementation takes different aspects in sparsely populated areas.

A rural development policy that features place is at once quite diverse. It for example is no longer useful to discuss policy interventions in terms of simplistic rural urban differences. The differences between rural places are the points of issue. This has found expression in the context of the new economic geography as it relates to space or distance and the differing economic endowments of regions. In the sense that the attributes studied by the new economic geography and the attributes that are now outside the market reflect differences that can generate value there is an argument for a placed based rural policy. The issue then becomes one of how to determine and develop the value from the differences among rural places.

Value comes form the preference for variety of households and from the similar motivations for choice of location by commercial and noncommercial organizations. It as well is form well established concepts of comparative advantage. What is new is the expansion of he scope of the policy domain to include the design of governmental and non governmental mechanisms to capture the more subtle attributes of place, and to develop the value of place based of the capacity to differentiate based on these attributes.
The integrating framework is mechanism design and strategic behavior. Both are modern ways of thinking about the interactions of agents that are different and may be seeking to gain from an interaction. Thus the framework is applicable within places as the process of identifying and building on attributes that differential them form others are under way. As well it is applicable in developing and understanding of the actions that may take place between or among places. The richness of the agenda for research and analysis that is suggested by this framework is compelling. At the same time the framework has practical guidelines that can help to guide the places and the national and state level agendas for rural policy.

Last, the emphasis on place and differentiation as well as on the attributes for which markets are not established or for which there is a market failure makes the new rural development policy framework much more local. With the refreshing exception of those who are working in the new economic geography and on building an understanding networking and how it affects economic activity as examples, there is been over attention to analysis that looks at a rural urban dichotomy or classifications of areas as more or less rural. The potential of these exercises is largely descriptive and not a source of policy prescription.

Place and the concept of differentiation as a key source of value advances a different analytical and policy analysis agenda before those interested in rural development and different requirements on the technical assistance and educational institutions that are serving rural America. First it has the potential for being far more prescriptive that past approaches. Second it is at once more grass roots orientated. Discovering the differentiating attributes of places and how to use them as sources of value and the strategic positioning of communities or places is work that requires close familiarity with the places themselves. On size fits all is not the implied technical assistance and education approach or the way o research and analyse the development strategies and successes of communities or places. 